Purdue University

Purdue e-Pubs

Prandtl-Number Effects and Generalized Correlations for Confined and Submerged Jet Impingement

C. -Y. Li

S V. Garimella

Purdue University, sureshg@purdue.edu

Follow this and additional works at: http://docs.lib.purdue.edu/coolingpubs

Li, C. -Y. and Garimella, S V., "Prandtl-Number Effects and Generalized Correlations for Confined and Submerged Jet Impingement" (2001). CTRC Research Publications. Paper 64.

http://docs.lib.purdue.edu/coolingpubs/64

This document has been made available through Purdue e-Pubs, a service of the Purdue University Libraries. Please contact epubs@purdue.edu for additional information. 


\title{
Prandtl-Number Effects and Generalized Correlations for Confined and Submerged Jet Impingement ${ }^{\text {II }}$
}

\author{
Chin-Yuan Li and Suresh V. Garimella ${ }^{\dagger}$ \\ School of Mechanical Engineering \\ Purdue University \\ West Lafayette, Indiana 47907-1288 U.S.A. \\ Phone: (765) 494-5621; FAX: (765) 494-0539 \\ Email: sureshg@ecn.purdue.edu
}

\begin{abstract}
The influence of fluid thermophysical properties on the heat transfer from confined and submerged impinging jets is experimentally investigated. Results from previous studies at low and high Prandtl numbers (using air and Fluorinert liquid FC-77, respectively) are supplemented by new experiments for an intermediate Prandtl number (using water). Local heat transfer coefficients are obtained from a discrete heat source under axisymmetric confined and submerged jets. The parameter ranges studied include: orifice diameters of 1.59 to $12.7 \mathrm{~mm}$, turbulent-flow Reynolds numbers of 4000 to 23000 , and orifice to heat-source spacings of 1 to 5 jet diameters. Generalized correlations for heat transfer rates are proposed based on these results, and are valid over the range of coolant Prandtl numbers from 0.7 to 25.2.
\end{abstract}

Keywords: Jets, liquid jets, air jets, confined impingement, design correlations, Prandtlnumber effects, thermophysical-property effects

ฯ Submitted for possible publication in International Journal of Heat and Mass Transfer, June 2000, and in revised form, October 26, 2000.

† Associate Professor; to whom correspondence should be addressed 


\section{Nomenclature}

$\mathrm{A}_{\mathrm{h}} \quad$ exposed area of heat source, $\mathrm{m}^{2}$

$A_{r} \quad$ ratio of impingement region area to heat-source area $(1.9 \mathrm{~d})^{2} / \mathrm{D}_{\mathrm{e}}{ }^{2}$

d orifice diameter, $\mathrm{mm}$

$D_{e} \quad$ effective heat-source diameter $\left(4 A_{h} / \pi\right)^{1 / 2}, \mathrm{~mm}$

$\mathrm{H} \quad$ jet-to-target spacing, $\mathrm{mm}$

h local convective heat transfer coefficient, $\mathrm{W} / \mathrm{m}^{2} \mathrm{~K}$

$\bar{h} \quad$ area-averaged heat transfer coefficient, $\mathrm{W} / \mathrm{m}^{2} \mathrm{~K}$

$\mathrm{h}_{0} \quad$ stagnation-point heat transfer coefficient, $\mathrm{W} / \mathrm{m}^{2} \mathrm{~K}$

$\mathrm{k}$ fluid thermal conductivity, $\mathrm{W} / \mathrm{mK}$

$l \quad$ orifice (plate) thickness, $\mathrm{mm}$

$\mathrm{Nu} \quad$ local Nusselt number (hd/k)

$\overline{\mathrm{Nu}} \quad$ area-averaged Nusselt number $(\bar{h} d / k)$

$N u_{0} \quad$ stagnation Nusselt number $\left(h_{0} d / k\right)$

Pr fluid Prandtl number

qout power dissipated by heat source, $\mathrm{W}$

$\mathrm{r} \quad$ radial distance from stagnation point, $\mathrm{mm}$

Re Reynolds number $(\mathrm{Ud} / v)$

$\mathrm{T}_{\mathrm{j}} \quad$ jet exit temperature, ${ }^{\circ} \mathrm{C}$

$\mathrm{T}_{\mathrm{s}} \quad$ heat-source surface temperature, ${ }^{\circ} \mathrm{C}$

$\mathrm{U}$ mean velocity of the jet, $\mathrm{m} / \mathrm{s}$

$\rho \quad$ fluid density, $\mathrm{kg} / \mathrm{m}^{3}$

$v \quad$ fluid kinematic viscosity, $\mathrm{m}^{2} / \mathrm{s}$ 
Subscript

f evaluated at film temperature

\section{Introduction}

Industrial applications of impinging jets have grown in number and variety. Examples include paper drying, steel mills, turbine-blade cooling, food processing and electronics cooling. In many instances, and especially in the cooling of high-density microelectronics in compact enclosures, the jets issue from orifices in a plate held parallel to the target surface. This renders the outflow from the impinging jets to being confined to a parallel-plates arrangement formed by the orifice plate and the target plate. Confinement has significant effects on the flow field of the jet, as well as on the heat transfer rates and distribution.

Although jet impingement has been extensively studied, and several excellent reviews of the state of the art are available [1, 2], the focus has been on free-surface or unconfined jets. The flow field in confined jets has been shown to be very different from that of unconfined jets [3], and the resulting heat transfer rates are not adequately predicted by unconfined-jet correlations. Recent studies of confined liquid [4] and air [5] jets have borne out previous reports [6] of the effects of confinement on the heat transfer coefficients.

A recent review article [7] presents a detailed discussion of heat transfer and flow fields in confined jet impingement. In spite of the large number of studies of jet impingement in the literature, a means for scaling the results between different fluids (with different thermophysical properties) and geometric parameters has not yet been developed. Attempts [5, 8] at proposing generalized correlations which represent the data on confined impingement of liquid and air jets have demonstrated the need for additional information concerning the effects of fluid thermophysical properties, turbulence levels, orifice geometry, and heater-to-orifice size. For 
example, there are interesting differences not only in the magnitudes but also in the parametric trends in heat transfer obtained with air when compared to FC-77 or water, these differences being related in part to the thermophysical properties of the fluid (Prandtl number of 0.7 for air versus 25 for FC-77) [7]. In the present study, the existing results for FC-77 (a perfluorinated, dielectric liquid) and air jets $[4,5]$ are supplemented by measurements of local and areaaveraged heat transfer coefficients with confined water jets using the same experimental approach. With results thus available over a wide range of fluid thermophysical properties, generalized correlations are proposed for predicting heat transfer in a variety of confined jet impingement applications.

The jets considered here are axisymmetric, normally impinging, confined and submerged, with the jet issuing into a quiescent region containing the same fluid. With the inclusion of the results for water jets obtained in the present study, the range of parameters for the database of results includes jet Reynolds number (4000 to 23000), orifice-to-target spacing (H/d of 1 to 5), fluid Prandtl number (0.7 to 25.2), and orifice diameter (1.59 to $12.7 \mathrm{~mm}$ ). Previous studies [4, 5] accounted for fluid properties in their correlations by employing a fixed Prandtl-number exponent $\left(\operatorname{Pr}^{0.4}\right)$. Although these approaches were successful in representing the experimental results considered, a more robust inclusion of fluid thermophysical-property effects is necessary for the correlations to be applicable over a wide range of fluids. The present work no longer uses a fixed exponent for Prandtl number, but instead, deduces this exponent based on an analysis of the experimental results.

It may be noted that generalized correlations for the pressure drop in the flow through square-edged orifices are available in Morris and Garimella [9] in terms of the orifice aspect ratio and mean jet velocity, and may be used in conjunction with the heat transfer correlations presented here in the design of impingement cooling systems. 


\section{Experimental Setup and Procedures}

The experiments were conducted in the transparent, closed-loop liquid jet impingement facility described in Refs. [4, 8]. Only important details of the setup are included here. Distilled water was used as the coolant in the experiments. The test section is made of plexiglass and houses a flow-conditioning plenum with an orifice plate attached at one end. The flow rate through the orifice was measured just downstream of the pump by one of two rotameters installed in parallel depending on the flowrate being set. Facing the orifice plate is a target plate containing the heat source as shown in Fig. 1. A T-type thermocouple measures the liquid temperature just prior to the orifice exit. Three different orifice plates were used in the experiments, each with a square-edged orifice of $1.59,3.18$, or $6.35 \mathrm{~mm}$ diameter in the center; the orifice length-to-diameter aspect ratio was the same for all experiments $(l / d=2)$. The orifice-to-target spacing $(\mathrm{H})$ was set such that $\mathrm{H} / \mathrm{d}=1,2,3$, or 4 .

Fluid from the orifice impinges on a heat source which is flush-mounted in the target plate. The heat source is made from a $0.075 \mathrm{~mm}$ thick stainless steel foil which is silver-brazed to copper bus bars, resulting in a $10 \times 10 \mathrm{~mm}$ square heat source. A 36-gage T-type thermocouple is attached to the underside of the foil at the center of the heat source. Conduction along the thin foil is minimal (lateral heat flow is $<0.5 \%$ of heat flow perpendicular to the foil [4]) such that local surface temperatures are obtained as the heat source (with the attached thermocouple) is moved laterally with respect to the stationary jet. This mimics an arrangement with a large number of thermocouples present under a stationary heat source. The foil heater is backed by polypropylene insulation $(\mathrm{k} \approx 0.12 \mathrm{~W} / \mathrm{mK})$, and the assembly is imbedded in an insulating polycarbonate holder. The heat source is oriented in the target plate such that the center of the jet traverses diagonally across the heated surface; temperature measurements could thus be obtained over the greatest possible traversal range. Since the extent of traversal of the jet 
with respect to the heat source is limited to the heated area (no unheated starting length), the thermal boundary layer development is not altered while the heat source moves relative to the jet. Further details of this measurement technique and the heat source construction are available in Refs. [4, 8].

The product of the measured current and voltage drop across the heater gives the power dissipated $\left(\mathrm{q}_{\mathrm{out}}\right)$. A conduction analysis (using measured temperatures at the top and bottom of the polypropylene backing) revealed that the heat lost through the underside of the foil was less than $2 \%$. This loss $\left(\mathrm{q}_{\mathrm{loss}}\right)$ was calculated as part of the data acquisition program and subtracted from the heat dissipation. The local heat transfer coefficient was calculated according to:

$$
h=\frac{q_{\text {out }}-q_{\text {loss }}}{A_{h}\left(T_{s}-T_{j}\right)}
$$

in which the heat fluxes and $\mathrm{T}_{\mathrm{j}}$ were constant in an experiment, while $\mathrm{T}_{\mathrm{s}}$ depended on location on the heat source. Temperatures were obtained at a large number of radial positions over $0 \leq \mathrm{r} \leq$ $7.2 \mathrm{~mm}$. The jet exit temperature was maintained in the range $8 \leq \mathrm{T}_{\mathrm{j}} \leq 12^{\circ} \mathrm{C}$ for all experiments. The data from each experiment were also area-averaged (over the area of the square heat source) to obtain an average heat transfer coefficient:

$$
\bar{h}=\frac{q_{\text {out }}}{\sum\left[\left(T_{s i}-T_{j}\right) \cdot A_{i}\right]}
$$

where $T_{\mathrm{si}}$ is the local surface temperature associated with the area element $A_{i}$ of the annular band straddling the location of each temperature measurement. At the corners of the square heat source, the area elements are fragmented annuli. The summation in the denominator of equation (2) was performed over the area of the heater, $A_{h}$. The average values for $\left(T_{s}-T_{j}\right)$ were adjusted to be in the range of $10-15^{\circ} \mathrm{C}$, to limit free-convection effects. The thermophysical properties in the nondimensional parameters $(\mathrm{Nu}, \mathrm{Re}$, and $\mathrm{Pr})$ were all evaluated at the jet inlet temperature, 
except in the correlations proposed in Tables 1 to 3 , for which they were evaluated at the film temperature.

A standard uncertainty analysis indicated that the uncertainty in the heat transfer coefficient was less than $\pm 5 \%$ (20:1 odds) in all cases. The primary contribution $(\approx 4 \%)$ to the uncertainty came from the heater-area measurement; uncertainty in temperature measurement was the other significant contributor. The uncertainties in the voltage and current were taken to be twice the standard deviation of the measured values. The uncertainty in each temperature measurement was taken to be $0.3^{\circ} \mathrm{C}$. Experiments performed over a period of months were found to have excellent repeatability, with the spread being never greater than 3\%; the heat transfer coefficient curves were also symmetric about the jet centerline.

\section{Results and Discussion}

Local and area-averaged heat transfer coefficients obtained from the water jet experiments of this study are first presented. Correlations are then developed for predicting heat transfer coefficients, based on results from prior work for $F C-77$ and air jets $[4,5]$ and the present results for water.

The distribution of local heat transfer coefficients on the heat source under an impinging water jet is illustrated in Fig. 2 for an orifice diameter of $6.35 \mathrm{~mm}$. Results for three different orifice-to-target spacings (differentiated by line style) and three Reynolds numbers (differentiated by symbol) are presented. The expected decrease in heat transfer coefficient with increasing radial distance from stagnation, as well as the increase in heat transfer with Reynolds number, are observed. To serve as a reference, results obtained in a previous study [4] using the same experimental facility but with a jet of FC-77 issuing from an orifice of the same diameter 
are also presented in this figure for $\mathrm{H} / \mathrm{d}=2$ and $\mathrm{Re}=8500$. The stagnation point heat transfer coefficient for the water jet is more than 4.7 times greater than that for the comparable FC-77 jet.

Figure 3 shows the radial distribution of the heat transfer coefficients as a function of orifice-to-target spacing and jet Reynolds number for a smaller orifice $(\mathrm{d}=3.18 \mathrm{~mm})$; one set of results for FC-77 is also included for comparison. Secondary peaks in heat transfer located at r/d $\approx 2$ are seen in the curves and are more pronounced for the smaller orifice-to-heat source spacings, and the higher jet Reynolds numbers. With an increase in Re, the secondary peaks move outward. This is consistent with the results of Obot et al. [6] for confined air jets, and Garimella and Rice [4] for confined liquid (FC-77) jets. As H/d increases, the prominence of the secondary peaks decreases until only an inflection point persists in their place. The stagnation heat transfer coefficient $\left(h_{0}\right)$ does not change much at a given Reynolds number with a change in orifice-to-target spacing from $\mathrm{H} / \mathrm{d}=1$ to 2 . For a further increase in $\mathrm{H} / \mathrm{d}$ to $4, h_{0}$ increases slightly. At small $\mathrm{H} / \mathrm{d}$, slight increases in $h_{0}$ with $\mathrm{H} / \mathrm{d}$ have been reported in other studies as well [4, 10-13], and an explanation in terms of the fluid mechanics of the jet was provided in Garimella [7]. With $\mathrm{H} / \mathrm{d}=2$ and $\mathrm{Re}=8500$, the stagnation heat transfer coefficient for the water jet is 3.7 times greater than that for the FC-77 jet; this increase in performance is smaller for the smaller orifice diameter than the increase seen for $d=6.35 \mathrm{~mm}$ in Fig. 2.

The local heat transfer coefficient distribution for different orifice diameters and $\mathrm{H} / \mathrm{d}$ is plotted in Fig. 4 for a fixed jet Reynolds number of $\mathrm{Re}=13000$. For the larger orifice diameter, the local heat transfer coefficient distribution is seen to be more uniform; for $\mathrm{d}=6.35 \mathrm{~mm}$, the heat source lies almost completely in the stagnation/impingement region. At a fixed Reynolds number, the higher jet velocity for a smaller orifice causes the stagnation heat transfer coefficients for $\mathrm{d}=1.59 \mathrm{~mm}$ to be roughly three times greater than those for $\mathrm{d}=6.35 \mathrm{~mm}$. It was pointed out in earlier studies on confined and submerged jet impingement [3-5, 8], that there 
is a distinct (and independent) effect of orifice diameter on heat transfer, which is not captured by the Nusselt-number nondimensionalization; this was found true with the water results of this study as well. An increase in orifice diameter was shown to cause an increase in the turbulence intensity of the jet $[3,14]$; the present results, when plotted as Nusselt number versus $r / d$ at a fixed Reynolds number (figure not shown), also showed an increase in $\mathrm{Nu}_{0}$ with $\mathrm{d}$. The jet exit turbulence levels (just downstream of the orifice) for jets of FC-77 were in the range of 10 to $20 \%$ for the square-edged nozzles considered in this study, as detailed in [3].

The area-averaged Nusselt numbers, plotted in Fig. 5 as a function of Reynolds number for the three different orifice diameters tested, also reveal a dependence on orifice diameter. As expected, the Nusselt number increases with Reynolds number for each test. The results are seen to lie in distinct groups for each orifice diameter. As the orifice diameter increases, the average Nusselt number increases. While this is attributable in part to the increase in $\mathrm{Nu}_{0}$ discussed above, the primary reason for the increase in $\overline{N u}$ with $\mathrm{d}$ is that as the orifice diameter increases, an increasing fraction of the heated area lies in the (more-effective) stagnation/impingement region.

\section{Correlations}

One of the two main goals of this work was to develop predictive correlations for the stagnation and area-averaged Nusselt numbers in confined and submerged jet impingement, based on experimental results obtained over a wide range of fluid thermophysical properties. The water jet results of the present study, together with those previously obtained for FC-77 [4] and air [5] using similar techniques and facilities, were used as a database to determine the effect

of fluid properties (Prandtl number), and thus to propose correlations that are valid for a range of fluids. 
All the results considered in this effort are for $1 \leq \mathrm{H} / \mathrm{d} \leq 4$, that is, for truly confined jets. Since the effect of $\mathrm{H} / \mathrm{d}$ on heat transfer coefficients is quite small in this $\mathrm{H} / \mathrm{d}$ range $[4$, 15 , etc.], this is not chosen as a parameter in the correlations.

The stagnation Nusselt numbers were correlated as a function of Reynolds number (nondimensionalized jet exit velocity), fluid properties (Pr), orifice geometry $(l / d)$, and effective heat source-to-orifice diameter ratio $\left(\mathrm{D}_{\mathrm{e}} / \mathrm{d}\right)$, with all fluid properties evaluated at the film temperature to account for temperature-dependent properties:

$$
N u_{0, f}=a \cdot \operatorname{Re}_{f}^{b} \cdot \operatorname{Pr}_{f}^{c} \cdot(\ell / d)^{d} \cdot\left(D_{e} / d\right)^{g}
$$

It has been shown $[5,16]$ that the heat source area (relative to the orifice area) influences the heat transfer rates obtained, especially for air jets; hence $D_{e}$ is included as a parameter in the correlations.

Since the primary flow direction and heat transfer rates in the impingement $(0 \leq \mathrm{r} \leq 1.9 \mathrm{~d}$ [17]) and wall-jet $(\mathrm{r}>1.9 \mathrm{~d})$ regions are quite different, correlations for the area-averaged Nusselt number included a combination of area-weighted contributions from these two regions. A similar approach has been used in the literature $[5,18,19]$. The form of the correlations was:

$$
\frac{\overline{N u_{f}}}{\operatorname{Pr}_{f}^{c}}=a \cdot \operatorname{Re}_{f}^{b} \cdot(\ell / d)^{d} \cdot\left(D_{e} / d\right)^{g} \cdot A_{r}+p \cdot \operatorname{Re}_{f}^{i} \cdot\left(D_{e} / d\right)^{j} \cdot\left(1-A_{r}\right)
$$

in which $\mathrm{A}_{\mathrm{r}}$ is the area of the impingement region normalized with the total heat source area, and $\left(1-A_{r}\right)$ represents the portion of the heat source which is in the wall-jet region. When $A_{r} \leq 1$, the second term in equation (4) drops out, and all of the heat source is in the impingement area. Since the effect of the orifice length-to-diameter ratio in the wall region has been shown to be small [8], $l / \mathrm{d}$ was omitted as a parameter in the second part of equation (4).

The heat transfer data were correlated with nonlinear least-squares curve fits using an adaptive combination of the Gauss-Newton and Levenberg-Marquardt algorithms. Correlations 
were first developed for the complete database of results for all fluids, without constraining the exponents of any of the correlation parameters. This led to equations (9), (14) and (19) in Tables

1 to 3 . Once the exponents were determined based on the composite database, the exponents for Prandtl number and orifice aspect ratio $(l / \mathrm{d})$ were fixed at these values when developing correlations for individual fluids. Correlations for stagnation and area-averaged heat transfer coefficients are listed in Tables 1 and 2 respectively: individual correlations for water, FC-77 and air are presented, in addition to a general correlation for liquids, and one for all fluids. Table 3 presents simpler, area-averaged Nusselt number correlations, in which the heat source is not divided into impingement and wall-jet regions using the parameter $A_{r}$. Ranges of $d, \operatorname{Pr}, \operatorname{Re}, H / d$, $l / d$ and $D_{e}$ over which these correlations are valid are listed in the tables, in addition to the average and maximum deviations of the data from the predictions. As might be expected, the correlations for individual fluids show lower deviations than do the composite correlations. The correlations in the tables also suggest that the area ratio $\left(D_{e} / d\right)$ has a strong effect on both the stagnation and area-averaged heat transfer coefficients.

Previous correlations in the literature were proposed for specific fluids $[4,5,8,15]$ for which the Prandtl-number exponent was arbitrarily set at 0.4 , and not obtained as a result of the correlation process. Since three different fluids were considered in the present work, with the Prandtl number ranging from 0.7 to 25.2 , the Prandtl-number dependence in the present correlations was obtained as a result of the curve-fitting process. The effect of the fluid Prandtl number on jet impingement heat transfer is brought out more clearly in Fig. 6, where the stagnation Nusselt numbers for air, water and FC-77 from all the experiments considered in this work are plotted (normalized with $\mathrm{Re}^{0.496}$ ) against Prandtl number.

Predictions from equation (9) are plotted in Fig. 7 along with the experimental data. Besides the good agreement in general, the figure shows that the data for air jets are slightly 
overpredicted by the composite correlation, while those for water jets are somewhat underpredicted. Predictions from the proposed composite correlation for stagnation Nusselt number are also compared to other correlations in the literature [8, 12, 20-22] in Fig. 8. This figure shows that the predictions from the current work agree with (and bound) those from existing correlations, which is to be expected in view of the larger ranges of parameters covered by the proposed correlations in this study.

Area-averaged Nusselt number correlations for individual fluids as well as an overall correlation for all fluids considered are presented in Tables 2 and 3. A comparison of the approaches in the two tables reveals that the separate consideration of the impingement and walljet regions using the parameter $A_{r}$ in the correlations, as included in Table 2, leads to somewhat lower average and maximum deviations. Predictions from equation (14) are plotted in Fig. 9 along with the experimental data for average Nusselt numbers. It must be remembered that the values for the area-averaged heat transfer coefficients depend directly on the area over which the averaging is performed. Clearly, the average heat transfer coefficient over a large heat source would be smaller in value than that over a small heat source. Ideally, a predictive correlation for the local distribution of heat transfer coefficients, $h(r)$, could be used to obtain an average over any area of choice simply by integration; however, such predictive correlations are difficult to develop due to the complex shapes of the local distributions and their confounding variations with many governing parameters. In Tables 2 and 3, the correlations for air jet impingement represent an average over a $20 \times 20 \mathrm{~mm}$ area, while the water and FC-77 jet results were averaged over a $10 \times 10 \mathrm{~mm}$ area. For the overall correlations, equations (14) and (19), local heat transfer results from air jet impingement were averaged over two different areas $-10 \times 10$ $\mathrm{mm}$ and $20 \times 20 \mathrm{~mm}-$ while the liquid results were available over the smaller area alone. The 
incorporation of the effective diameter $D_{e}$ and the area ratio $A_{r}$ in the correlations allow predictions over a range of heated areas.

The correlations presented here are most applicable in electronics cooling applications, where small, discrete heat sources are considered.

\section{Summary}

The local and average heat transfer coefficients on a small, square heat source in confined and submerged water jet impingement were investigated as a function of orifice-to-target spacing, jet Reynolds number, and orifice geometry, to supplement results for similar configurations previously available for jets of air and FC-77. The trends of variation of heat transfer in the case of water jets were quite similar to the observations regarding FC-77 jets [4], with the main difference being the significantly higher magnitudes of heat transfer coefficients obtained with the water jets.

Generalized predictive correlations were proposed for stagnation and area-averaged Nusselt numbers based on the experimental database of results for air, water, and FC-77, spanning a wide range of Prandtl numbers. Composite correlations spanning all the fluids were developed, as were separate correlations for individual fluids. The correlation parameters included the jet Reynolds number, fluid Prandtl number, orifice aspect ratio, and the effective heat source-to-orifice diameter ratio. The appropriate Prandtl-number exponent was determined as a result of the correlation process, and was not constrained arbitrarily. 


\section{References}

1. B. W. Webb, C. F. Ma, Single-phase liquid jet impingement heat transfer, Adv. Heat Transfer 26 (1995) 105-217.

2. J. H. Lienhard, Liquid jet impingement, Chapter 4, Ann. Rev. Heat Transfer, 6 (1995) 199270.

3. J. A. Fitzgerald, S. V. Garimella, A study of the flow field of a confined and submerged impinging jet, Int. J. Heat Mass Transfer 41 (1998) 1025-1034.

4. S. V. Garimella, R. A. Rice, Confined and submerged liquid jet impingement heat transfer, $J$. Heat Transfer 117 (1995) 871-877.

5. V. P. Schroeder, S. V. Garimella, Heat transfer from a discrete heat source in confined air jet impingement, Procs. $11^{\text {th }}$ Int. Heat Transfer Conf., Kyongju, Korea, 1998, Vol. 5, pp. 451456.

6. N. T. Obot, W. J. M. Douglas, A. S. Mujumdar, Effect of semi-confinement on impingement heat transfer, Procs. $7^{\text {th }}$ Int. Heat Transfer Conf., 1982, Vol. 3, pp. 395-400.

7. S. V. Garimella, Heat transfer and flow fields in confined jet impingement, Chapter 7, Ann. Rev. Heat Transfer 11 (1999) 413-494.

8. S. V. Garimella, B. Nenaydykh, Nozzle-geometry effects in liquid jet impingement heat transfer, Int. J. Heat Mass Transfer 39 (1996) 2915-2923.

9. G. K. Morris, S. V. Garimella, Orifice and impingement flow fields in confined jet impingement, J. Electronic Packaging 120 (1998) 68-72.

10. R. Gardon, J. C. Akfirat, The role of turbulence in determining the heat transfer characteristics of impinging jets, Int. J. Heat Mass Transfer 8 (1965) 1261-1272. 
11. J. W. Baughn, A. E. Hechanova, X. Yan, An experimental study of entrainment effects on the heat transfer from a flat surface to a heated circular impinging jet, ASME/JSME Thermal Engineering Procs. Vol. 3 (1991) pp. 143-149.

12. H. Sun, C. F. Ma, W. Nakayama, Local characteristics of convective heat transfer from simulated microelectronic chips to impinging submerged round water jets, J. Electronic Packaging 115 (1993) 71-77.

13. C. F. Ma, H. Sun, H. Auracher, T. Gomi, Local convective heat transfer from vertical heated surfaces to impinging circular jets, Procs. $9^{\text {th }}$ Int. Heat Transfer Conf., Hemisphere, Washington, D.C., 1990, Vol. 2, pp. 441-446.

14. J. A. Fitzgerald, S. V. Garimella, Flow field effects on heat transfer in confined jet impingement, J. Heat Transfer 119 (1997) 630-632.

15. C. F. Ma, A. E. Bergles, Convective heat transfer on a small vertical heated surface to an impinging circular liquid jet, Heat Transfer Science and Technology (B. X. Wang, Ed.), Hemisphere, Washington, D.C., 1990, pp. 193-200.

16. Y. J. San, C. H. Huang, M. H. Shu, Impingement cooling of a confined circular air jet, Int. J. Heat Mass Transfer 40 (1997) 1355-1364.

17. H. Martin, Heat and mass transfer between impinging gas jets and solid surfaces, Adv. Heat Transfer 13 (1977) 1-60.

18. S. Sitharamayya, K. Subba Raju, Heat transfer between an axisymmetric jet and a plate held normal to the flow, Can. J. Chem. Eng. 47 (1969) 365-368.

19. D. J. Womac, S. Ramadhyani, F. P. Incropera, Correlating equations for impingement cooling of the small heat sources with single circular liquid jets, J. Heat Transfer 115 (1993) 106-115. 
20. C. T. Chang, G. Kocamustafaogullari, F. Landis, S. Downing, Single and multiple liquid jetimpingement heat transfer, Heat Transfer in Turbulent Flows, 1993, ASME HTD-246, pp. 43-52.

21. C. F. Ma, A. E. Bergles, Convective heat transfer on a small vertical heated surface in an impinging circular liquid jet, Heat Transfer Science and Technology, Hemisphere, Washington D.C., 1990, pp. 193-200.

22. J. Stevens, B. W. Webb, Local heat transfer coefficients under an axisymmetric, single-phase liquid jet, J. Heat Transfer 113 (1991) 71-78. 
Table 1. Stagnation-Point Nusselt Number Correlations.

\begin{tabular}{|c|c|c|c|}
\hline Fluid & $\begin{array}{c}\text { Experimental } \\
\text { Parameters }\end{array}$ & Correlations $^{\dagger}$ & $\begin{array}{c}\text { Average } \\
\text { (Maximum) } \\
\text { Deviation } \\
\%\end{array}$ \\
\hline Water & $\begin{array}{ll}\mathrm{d} & 1.59 \sim 6.35 \mathrm{~mm} \\
\mathrm{Pr} & 7.1 \sim 9.2 \\
\mathrm{Re} & 8500 \sim 23000 \\
\mathrm{H} / \mathrm{d} & 1 \sim 4 \\
l / \mathrm{d} & 2 \\
\mathrm{D}_{\mathrm{e}} & 11.28 \mathrm{~mm} \\
\end{array}$ & $N u_{0}=1.039 \operatorname{Re}^{0.515} \operatorname{Pr}^{0.444}\left(\frac{\ell}{d}\right)^{-0.058}\left(\frac{D_{e}}{d}\right)^{-0.246} \ldots . .(5)$ & $4.68(12.07)$ \\
\hline FC-77 & $\begin{array}{ll}\mathrm{d} & 1.59 \sim 6.35 \mathrm{~mm} \\
\mathrm{Pr} & 20 \sim 25.2 \\
\mathrm{Re} & 4000 \sim 23000 \\
\mathrm{H} / \mathrm{d} & 1 \sim 5 \\
l / \mathrm{d} & 0.25 \sim 12 \\
\mathrm{D}_{\mathrm{e}} & 11.28 \mathrm{~mm} \\
\end{array}$ & $N u_{0}=1.738 \operatorname{Re}^{0.480} \operatorname{Pr}^{0.444}\left(\frac{\ell}{d}\right)^{-0.058}\left(\frac{D_{e}}{d}\right)^{-0.301} \ldots \ldots$ (6) & $4.93(12.34)$ \\
\hline Air ${ }^{*}$ & $\begin{array}{ll}\mathrm{d} & 3.18 \sim 12.7 \mathrm{~mm} \\
\mathrm{Pr} & 0.7 \\
\mathrm{Re} & 5000 \sim 23000 \\
\mathrm{H} / \mathrm{d} & 1 \sim 4 \\
l / \mathrm{d} & 1 \\
\mathrm{D}_{\mathrm{e}} & 22.56 \mathrm{~mm}\end{array}$ & $N u_{0}=1.671 \operatorname{Re}^{0.483} \operatorname{Pr}^{0.444}\left(\frac{\ell}{d}\right)^{-0.058}\left(\frac{D_{e}}{d}\right)^{-0.226} \quad \ldots .(7)$ & $4.90(11.92)$ \\
\hline Liquids & $\begin{array}{ll}\mathrm{d} & 1.59 \sim 6.35 \mathrm{~mm} \\
\mathrm{Pr} & 7.1 \sim 25.2 \\
\mathrm{Re} & 4000 \sim 23000 \\
\mathrm{H} / \mathrm{d} & 1 \sim 5 \\
l / \mathrm{d} & 0.25 \sim 12 \\
\mathrm{D}_{\mathrm{e}} & 11.28 \mathrm{~mm}\end{array}$ & $N u_{0}=1.409 \operatorname{Re}^{0.497} \operatorname{Pr}^{0.444}\left(\frac{\ell}{d}\right)^{-0.058}\left(\frac{D_{e}}{d}\right)^{-0.272} \ldots \ldots$ (8) & $9.27(26.69)$ \\
\hline $\begin{array}{l}\text { All } \\
\text { fluids }\end{array}$ & $\begin{array}{ll}\mathrm{d} & 1.59 \sim 12.7 \mathrm{~mm} \\
\mathrm{Pr} & 0.7 \sim 25.2 \\
\mathrm{Re} & 4000 \sim 23000 \\
\mathrm{H} / \mathrm{d} & 1 \sim 5 \\
l / \mathrm{d} & 0.25 \sim 12 \\
\mathrm{D}_{\mathrm{e}} & 11.28 \sim 22.56 \mathrm{~mm}\end{array}$ & $N u_{0}=1.427 \operatorname{Re}^{0.496} \operatorname{Pr}^{0.444}\left(\frac{\ell}{d}\right)^{-0.058}\left(\frac{D_{e}}{d}\right)^{-0.272} \ldots \ldots$ (9) & $9.08(27.12)$ \\
\hline
\end{tabular}

${ }_{\dagger}$ Thermophysical properties evaluated at film temperature

*The area of the heater for air jets was $20 \times 20 \mathrm{~mm}^{2}$ 
Table 2. Area-averaged Nusselt Number Correlations.

\begin{tabular}{|c|c|c|c|}
\hline Fluid & $\begin{array}{c}\text { Experimental } \\
\text { Parameters }\end{array}$ & Correlations $^{\dagger}$ & $\begin{array}{c}\text { Average } \\
\text { (Maximum) } \\
\text { Deviation } \\
\%\end{array}$ \\
\hline Water & $\begin{array}{ll}\mathrm{d} & 1.59 \sim 6.35 \mathrm{~mm} \\
\mathrm{Pr} & 7.1 \sim 9.2 \\
\mathrm{Re} & 8500 \sim 23000 \\
\mathrm{H} / \mathrm{d} & 1 \sim 4 \\
l / \mathrm{d} & 2 \\
\mathrm{D}_{\mathrm{e}} & 11.28 \mathrm{~mm}\end{array}$ & $\begin{aligned} \overline{N u} & =0.676 \operatorname{Re}^{0.555} \operatorname{Pr}^{0.441}\left(\frac{\ell}{d}\right)^{-0.071}\left(\frac{D_{e}}{d}\right)^{-0.276} \cdot A_{r} \\
& +1.113 \operatorname{Re}^{0.637} \operatorname{Pr}^{0.441}\left(\frac{D_{e}}{d}\right)^{-1.062} \cdot\left(1-A_{r}\right)\end{aligned}$ & $3.52(9.89)$ \\
\hline FC-77 & $\begin{array}{ll}\mathrm{d} & 1.59 \sim 6.35 \mathrm{~mm} \\
\mathrm{Pr} & 20 \sim 25.2 \\
\mathrm{Re} & 4000 \sim 23000 \\
\mathrm{H} / \mathrm{d} & 1 \sim 5 \\
l / \mathrm{d} & 0.25 \sim 12 \\
\mathrm{D}_{\mathrm{e}} & 11.28 \mathrm{~mm}\end{array}$ & $\begin{aligned} \overline{N u} & =1.347 \operatorname{Re}^{0.493} \operatorname{Pr}^{0.441}\left(\frac{\ell}{d}\right)^{-0.071}\left(\frac{D_{e}}{d}\right)^{-0.276} \cdot A_{r} \\
& +0.457 \operatorname{Re}^{0.736} \operatorname{Pr}^{0.441}\left(\frac{D_{e}}{d}\right)^{-1.027} \cdot\left(1-A_{r}\right)\end{aligned}$ & $4.82(15.77)$ \\
\hline Air* & $\begin{array}{ll}\mathrm{d} & 3.18 \sim 12.7 \mathrm{~mm} \\
\mathrm{Pr} & 0.7 \\
\mathrm{Re} & 5000 \sim 23000 \\
\mathrm{H} / \mathrm{d} & 1 \sim 4 \\
l / \mathrm{d} & 1 \\
\mathrm{D}_{\mathrm{e}} & 22.56 \mathrm{~mm} \\
\end{array}$ & $\begin{aligned} \overline{N u} & =1.828 \operatorname{Re}^{0.473} \operatorname{Pr}^{0.441}\left(\frac{\ell}{d}\right)^{-0.071}\left(\frac{D_{e}}{d}\right)^{-0.312} \cdot A_{r} \\
& +0.501 \operatorname{Re}^{0.724} \operatorname{Pr}^{0.441}\left(\frac{D_{e}}{d}\right)^{-1.062} \cdot\left(1-A_{r}\right)\end{aligned}$ & 3.98 (13.19) \\
\hline Liquids & $\begin{array}{ll}\mathrm{d} & 1.59 \sim 6.35 \mathrm{~mm} \\
\mathrm{Pr} & 7.1 \sim 25.2 \\
\mathrm{Re} & 4000 \sim 23000 \\
\mathrm{H} / \mathrm{d} & 1 \sim 5 \\
l / \mathrm{d} & 0.25 \sim 12 \\
\mathrm{D}_{\mathrm{e}} & 11.28 \mathrm{~mm}\end{array}$ & $\begin{aligned} \overline{N u} & =1.064 \operatorname{Re}^{0.513} \operatorname{Pr}^{0.441}\left(\frac{\ell}{d}\right)^{-0.071}\left(\frac{D_{e}}{d}\right)^{-0.266} \cdot A_{r} \\
& +1.291 \operatorname{Re}^{0.630} \operatorname{Pr}^{0.441}\left(\frac{D_{e}}{d}\right)^{-1.063} \cdot\left(1-A_{r}\right)\end{aligned}$ & $8.03(20.08)$ \\
\hline $\begin{array}{l}\text { All } \\
\text { fluids }\end{array}$ & $\begin{array}{ll}\mathrm{d} & 1.59 \sim 12.7 \mathrm{~mm} \\
\mathrm{Pr} & 0.7 \sim 25.2 \\
\mathrm{Re} & 4000 \sim 23000 \\
\mathrm{H} / \mathrm{d} & 1 \sim 5 \\
l & 0.25 \sim 12 \\
\mathrm{D}_{\mathrm{e}} & 11.28 \sim 22.56 \mathrm{~mm}\end{array}$ & $\begin{aligned} \overline{N u} & =1.179 \operatorname{Re}^{0.504} \operatorname{Pr}^{0.441}\left(\frac{\ell}{d}\right)^{-0.071}\left(\frac{D_{e}}{d}\right)^{-0.283} \cdot A_{r} \\
& +1.211 \operatorname{Re}^{0.637} \operatorname{Pr}^{0.441}\left(\frac{D_{e}}{d}\right)^{-1.062} \cdot\left(1-A_{r}\right)\end{aligned}$ & 8.57 (27.79) \\
\hline
\end{tabular}

${ }^{\dagger}$ Thermophysical properties evaluated at film temperature

*Averaging area of the heater for air jets was $20 \times 20 \mathrm{~mm}^{2}$ 
Table 3. Area-averaged Nusselt Number Correlations without using $A_{r}$.

\begin{tabular}{|c|c|c|c|}
\hline Fluid & $\begin{array}{c}\text { Experimental } \\
\text { Parameters }\end{array}$ & Correlations $^{\dagger}$ & $\begin{array}{l}\text { Average } \\
\text { (Maximum) } \\
\text { Deviation }\end{array}$ \\
\hline Water & $\begin{array}{ll}\mathrm{d} & 1.59 \sim 6.35 \mathrm{~mm} \\
\mathrm{Pr} & 7.1 \sim 9.2 \\
\mathrm{Re} & 8500 \sim 23000 \\
\mathrm{H} / \mathrm{d} & 1 \sim 4 \\
l / \mathrm{d} & 2 \\
\mathrm{D}_{\mathrm{e}} & 11.28 \mathrm{~mm} \\
\end{array}$ & $\overline{N u}=0.690 \operatorname{Re}^{0.555} \operatorname{Pr}^{0.452}\left(\frac{\ell}{d}\right)^{-0.07}\left(\frac{D_{e}}{d}\right)^{-0.348} \ldots \ldots(15)$ & $4.14(12.67)$ \\
\hline FC-77 & $\begin{array}{ll}\mathrm{d} & 1.59 \sim 6.35 \mathrm{~mm} \\
\mathrm{Pr} & 20 \sim 25.2 \\
\mathrm{Re} & 4000 \sim 23000 \\
\mathrm{H} / \mathrm{d} & 1 \sim 5 \\
l / \mathrm{d} & 0.25 \sim 12 \\
\mathrm{D}_{\mathrm{e}} & 11.28 \mathrm{~mm} \\
\end{array}$ & $\overline{N u}=1.147 \operatorname{Re}^{0.518} \operatorname{Pr}^{0.452}\left(\frac{\ell}{d}\right)^{-0.07}\left(\frac{D_{e}}{d}\right)^{-0.411} \ldots . .(16)$ & $5.51(28.40)$ \\
\hline Air* & $\begin{array}{ll}\mathrm{d} & 3.18 \sim 12.7 \mathrm{~mm} \\
\mathrm{Pr} & 0.7 \\
\mathrm{Re} & 5000 \sim 23000 \\
\mathrm{H} / \mathrm{d} & 1 \sim 4 \\
l / \mathrm{d} & 1 \\
\mathrm{D}_{\mathrm{e}} & 22.56 \mathrm{~mm} \\
\end{array}$ & $\overline{N u}=1.699 \operatorname{Re}^{0.492} \operatorname{Pr}^{0.452}\left(\frac{\ell}{d}\right)^{-0.07}\left(\frac{D_{e}}{d}\right)^{-0.453} \ldots . .(17)$ & 7.97 (40.39) \\
\hline Liquids & $\begin{array}{ll}\mathrm{d} & 1.59 \sim 6.35 \mathrm{~mm} \\
\mathrm{Pr} & 7.1 \sim 25.2 \\
\mathrm{Re} & 8500 \sim 23000 \\
\mathrm{H} / \mathrm{d} & 1 \sim 5 \\
l / \mathrm{d} & 0.25 \sim 12 \\
\mathrm{D}_{\mathrm{e}} & 11.28 \mathrm{~mm} \\
\end{array}$ & $\overline{N u}=0.926 \operatorname{Re}^{0.535} \operatorname{Pr}^{0.452}\left(\frac{\ell}{d}\right)^{-0.07}\left(\frac{D_{e}}{d}\right)^{-0.385} \ldots . .(18)$ & $8.21(25.74)$ \\
\hline $\begin{array}{l}\text { All } \\
\text { fluids }\end{array}$ & $\begin{array}{ll}\mathrm{d} & 1.59 \sim 12.7 \mathrm{~mm} \\
\mathrm{Pr} & 0.7 \sim 25.2 \\
\mathrm{Re} & 4000 \sim 23000 \\
\mathrm{H} / \mathrm{d} & 1 \sim 5 \\
l / \mathrm{d} & 0.25 \sim 12 \\
\mathrm{D}_{\mathrm{e}} & 11.28 \sim 22.56 \mathrm{~mm}\end{array}$ & $\overline{N u}=0.978 \operatorname{Re}^{0.529} \operatorname{Pr}^{0.452}\left(\frac{\ell}{d}\right)^{-0.07}\left(\frac{D_{e}}{d}\right)^{-0.381} \ldots .(19)$ & $9.04(27.46)$ \\
\hline
\end{tabular}

${ }^{\dagger}$ Thermophysical properties evaluated at film temperature

*Averaging area of the heater for air jets was $20 \times 20 \mathrm{~mm}^{2}$ 


\section{Figure Captions}

Figure 1. Schematic of experimental test section.

Figure 2. Variation of local heat transfer coefficient distribution with $\mathrm{H} / \mathrm{d}$ and Reynolds number for an orifice diameter of $6.35 \mathrm{~mm}$.

Figure 3. Variation of local heat transfer coefficient distribution with $\mathrm{H} / \mathrm{d}$ and Reynolds number for an orifice diameter of $3.18 \mathrm{~mm}$.

Figure 4. Variation of local heat transfer coefficient distribution with $\mathrm{H} / \mathrm{d}$ and orifice diameter for $\operatorname{Re}=13000$.

Figure 5. Variation of area-averaged Nusselt numbers with Reynolds number for the three jets at various $\mathrm{H} / \mathrm{d}$.

Figure 6. Effect of fluid Prandtl number on the stagnation heat transfer from the experiments considered in this study.

Figure 7. Comparison of experimental data for stagnation Nusselt numbers with predictions from the proposed correlation, equation (9).

Figure 8. Comparison of the proposed correlation for stagnation Nusselt numbers (equation 9) with predictions from other correlations in the literature.

Figure 9. Comparison of experimental data for area-averaged Nusselt numbers with predictions from the proposed correlation, equation (14). 


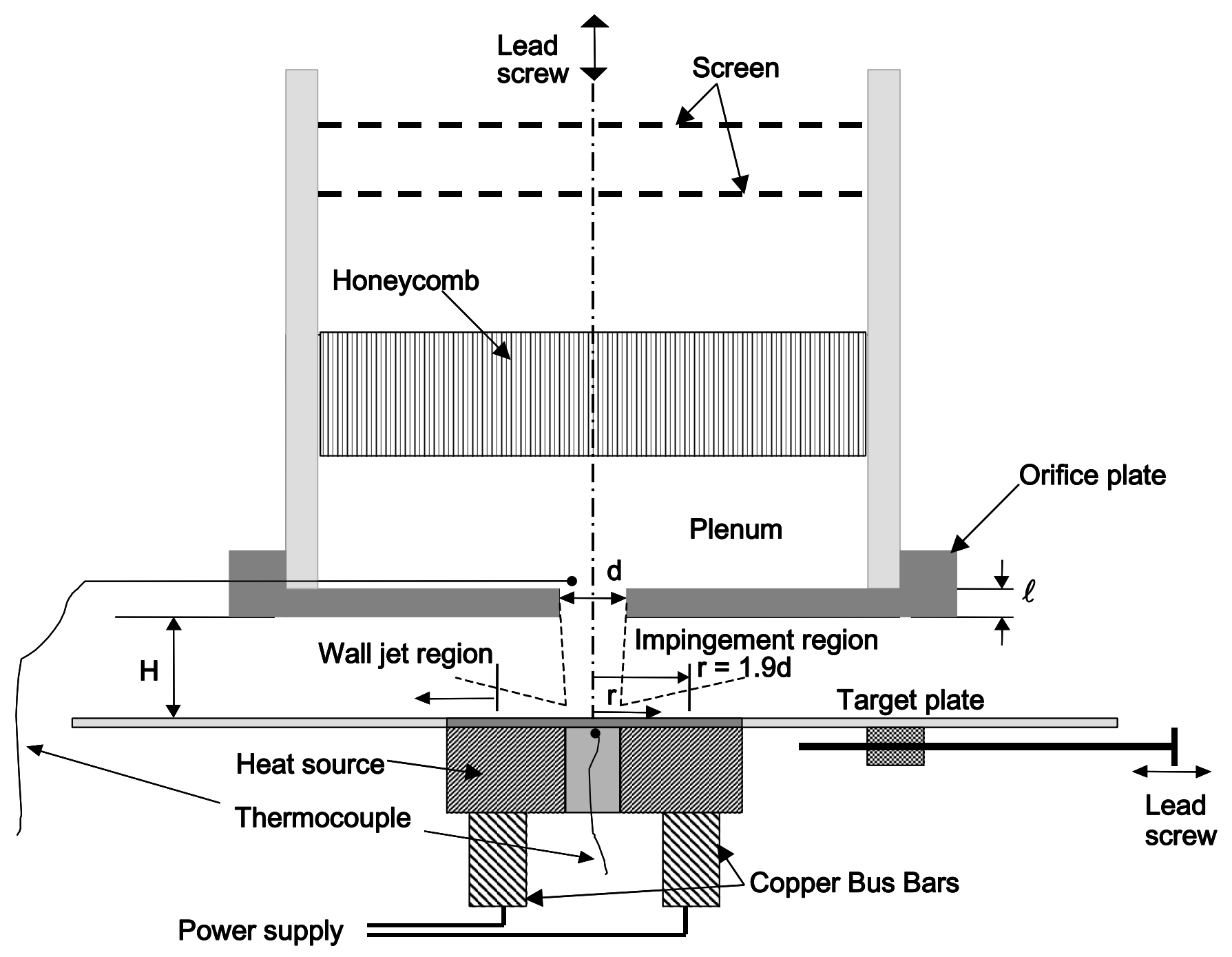

Li and Garimella, Fig. 1 


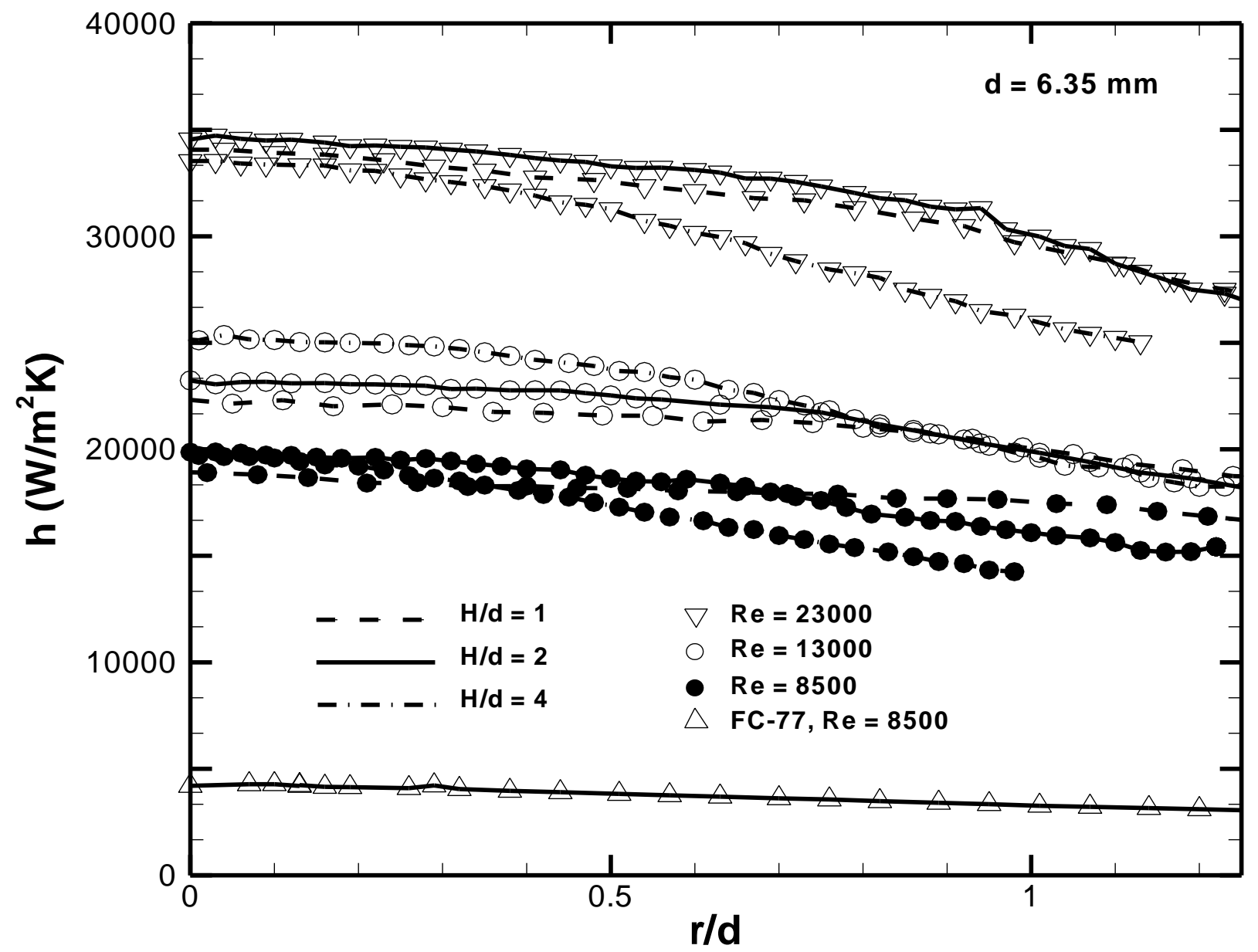

Li and Garimella, Fig. 2 


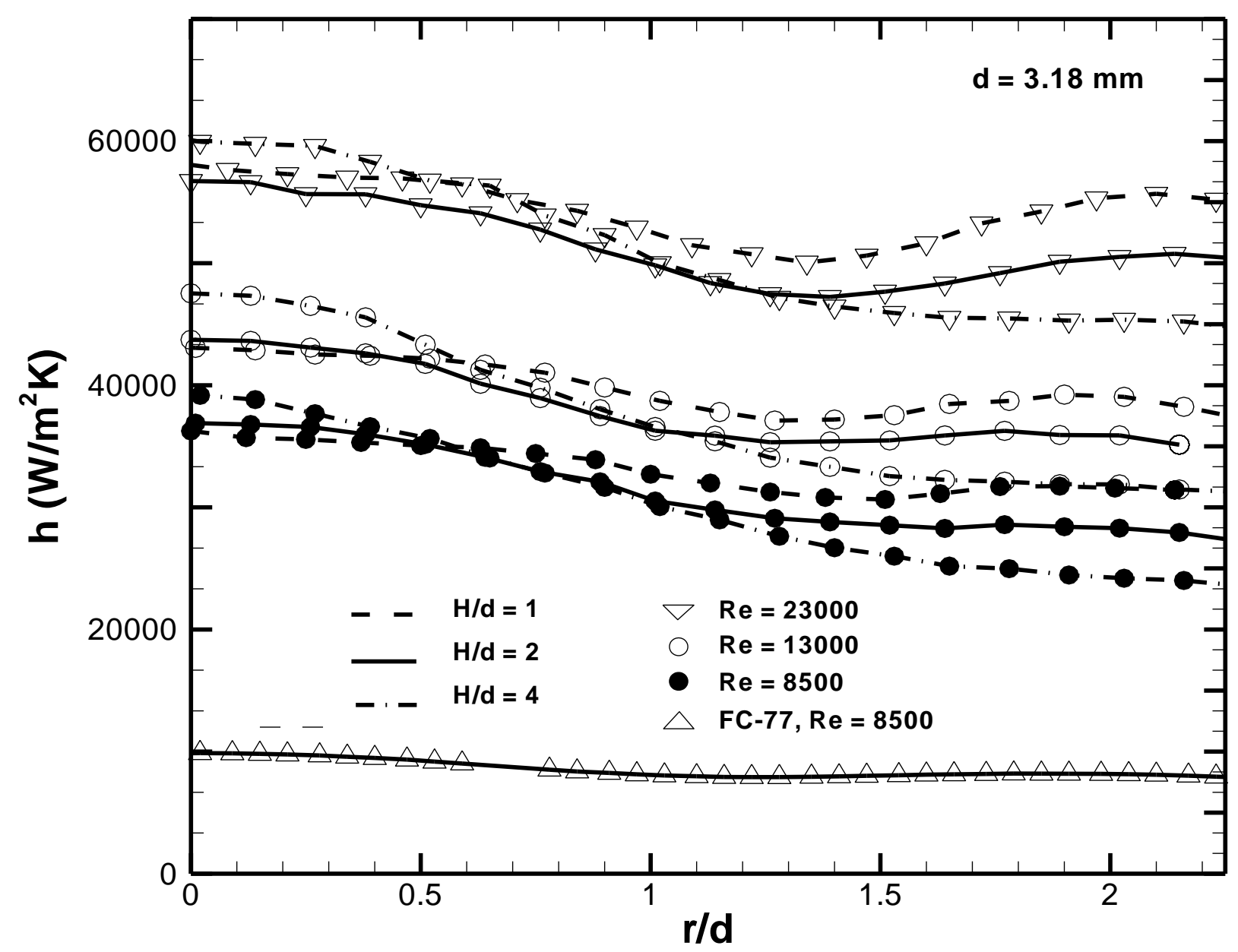

Li and Garimella, Fig. 3 


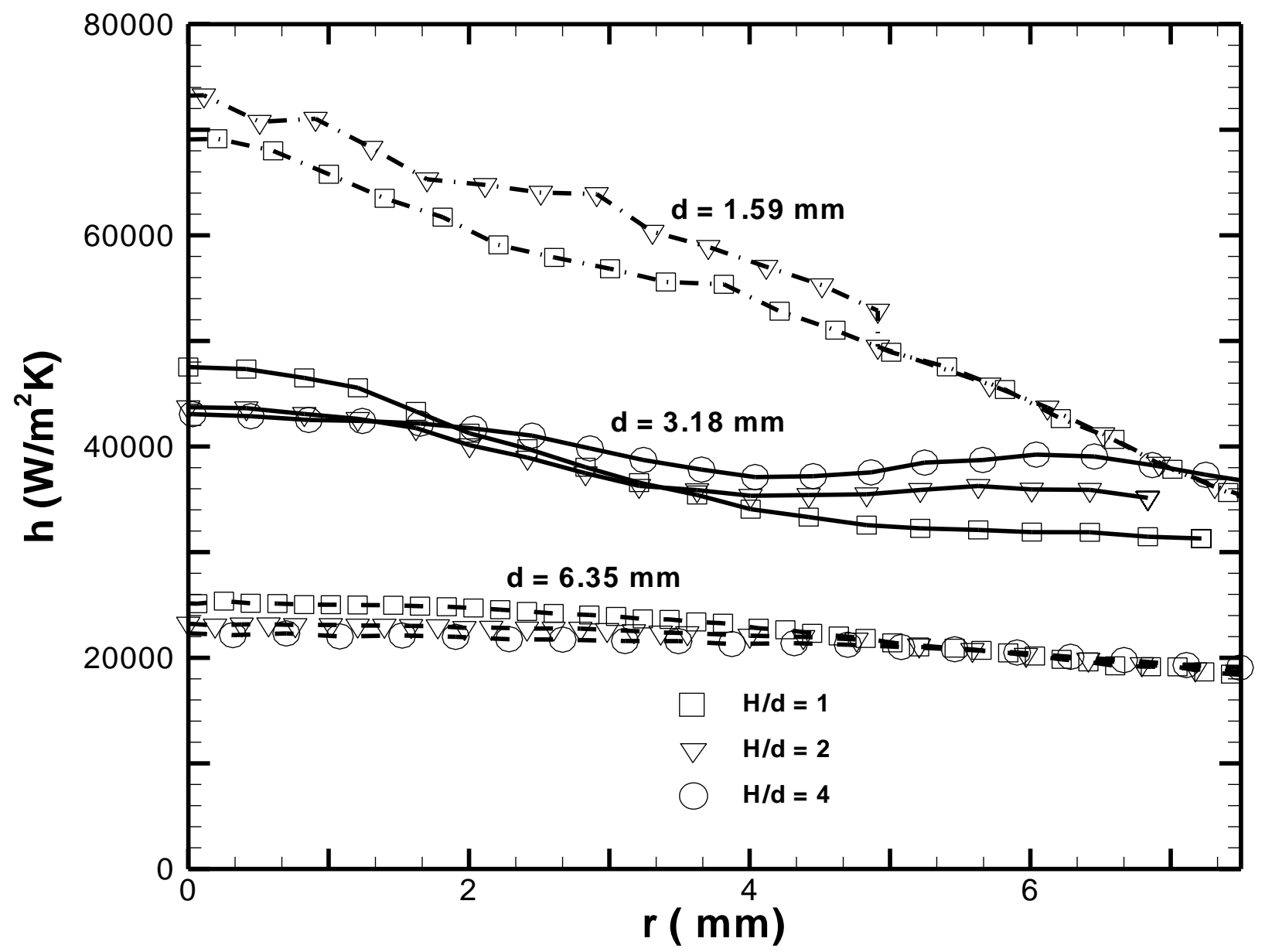

Li and Garimella, Fig. 4 


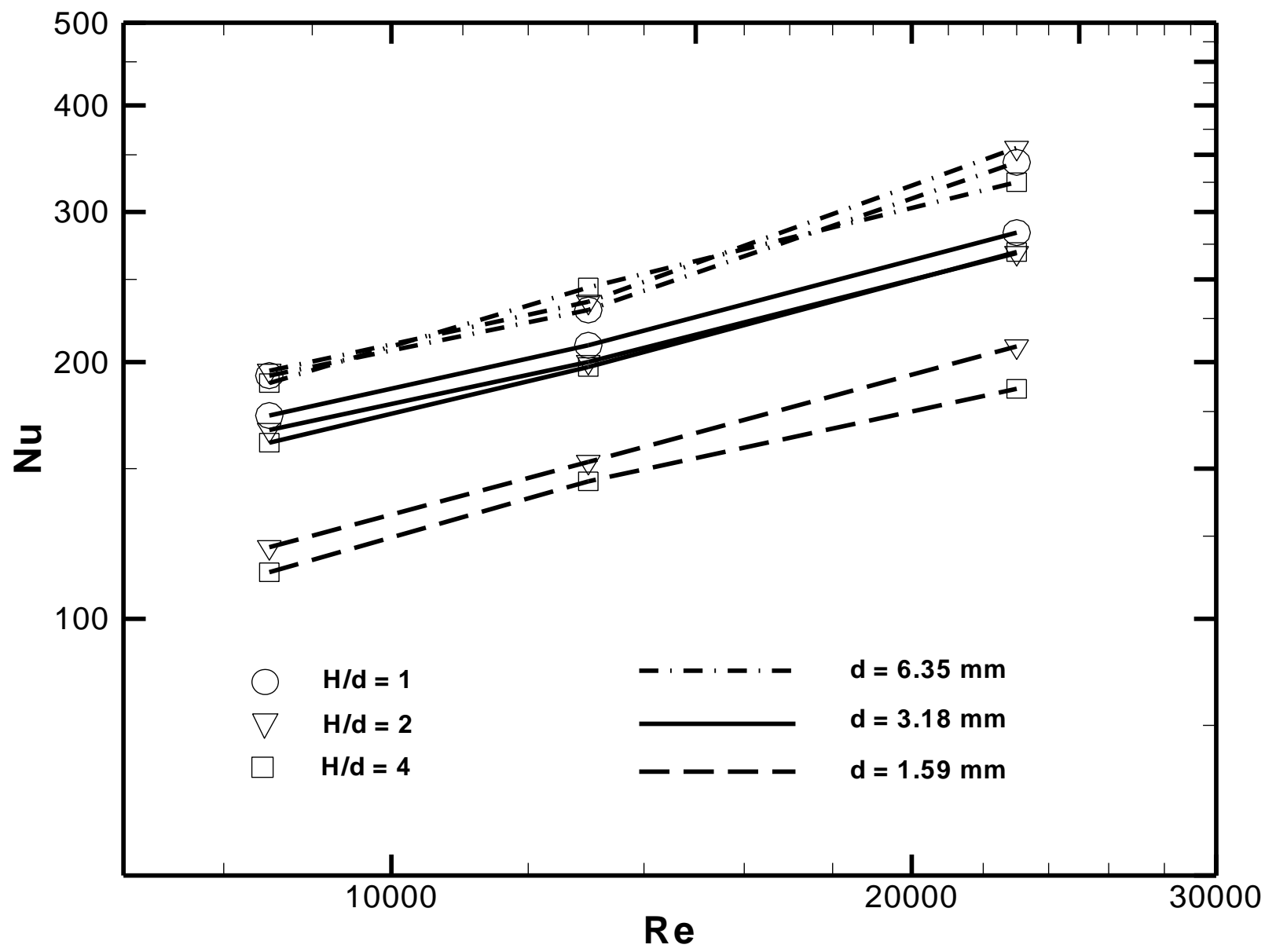

Li and Garimella, Fig. 5 


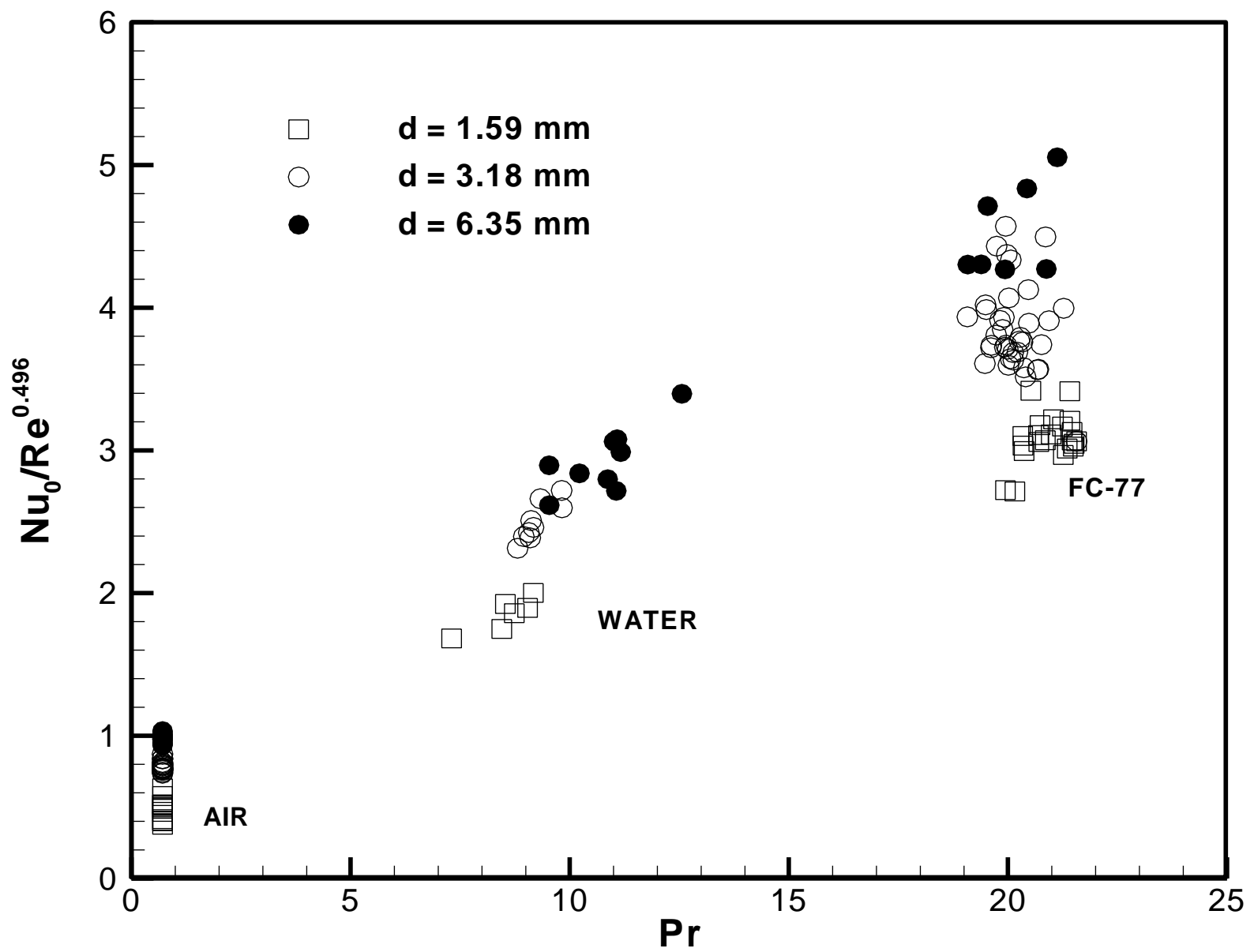

Li and Garimella, Fig. 6 


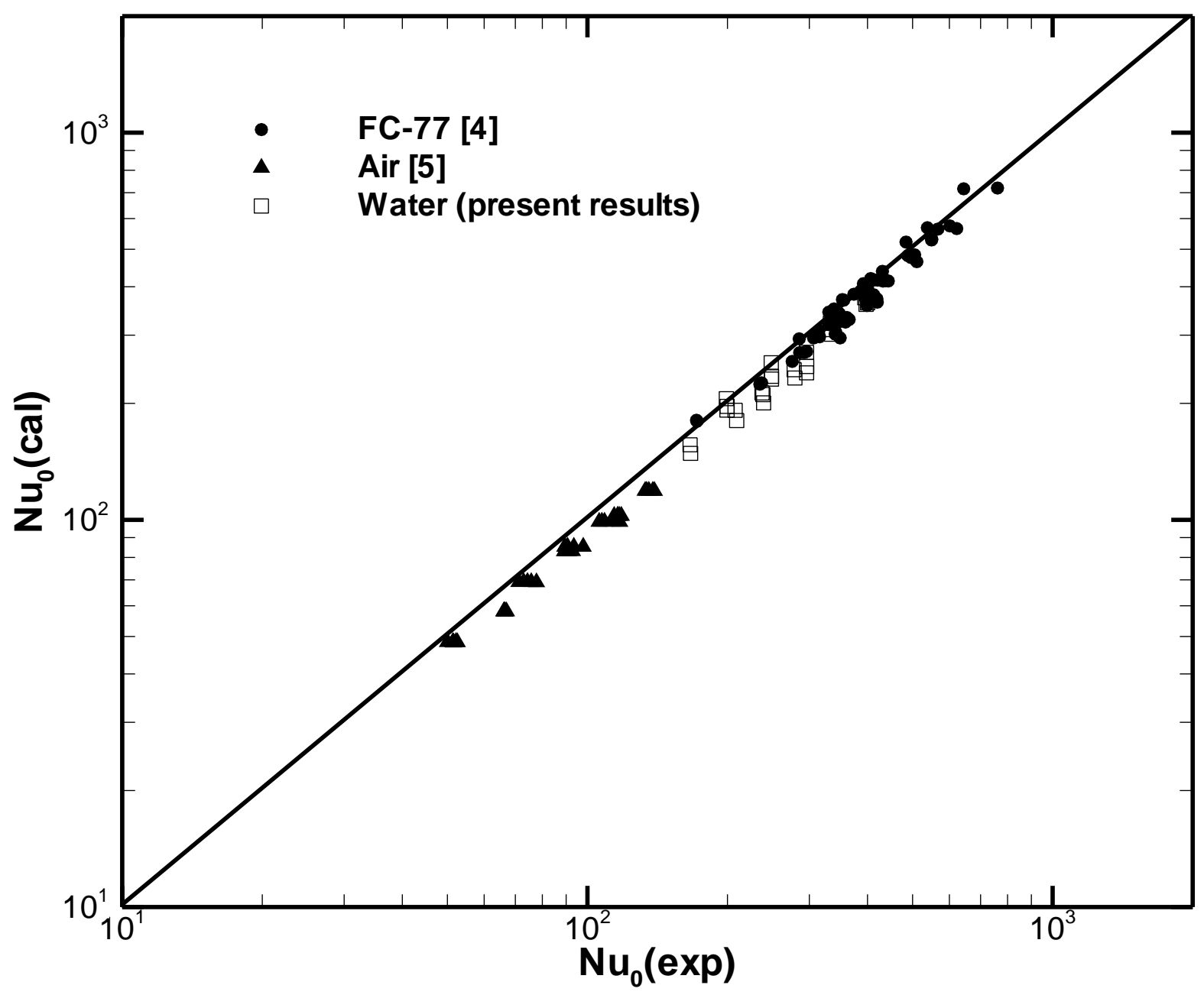

Li and Garimella, Fig. 8 
Li and Garimella, Fig. 9 